\title{
A Preliminary Study of Fair-Weather Atmospheric Electric Field at a High Altitude Station (Shillong) $25^{\circ} \mathrm{N}, \mathbf{9 1}^{\circ} \mathrm{E}$.
}

\author{
V. Valeo ${ }^{1,2 *}$, P. V. Koparkar ${ }^{2}$ \\ $I *$ Department of Physics, North-Eastern Hill University, Shillong, India \\ 2 Department of Basic Sciences and Social Sciences, North-Eastern Hill University, Shillong, India
}

\begin{abstract}
Atmospheric electric field at the surface of the earth is affected by the local meteorological processes including solar irradiance. In the study reported here, the surface measurements of atmospheric electric potential gradient on selected fair-weather days was evaluated for diurnal and monthly variations. The measurements were carried out over the period from January 2017 to June 2017. The measurement demonstrated that on fair-weather days the diurnal potential gradient showed positive correlation to temperature and solar irradiance. The relative humidity however exhibited negative correlation with temperature and solar irradiance. The study demonstrates that the potential gradient is dependent on solar irradiance, temperature and humidity.
\end{abstract}

Keyword: Potential Gradient, atmospheric electric field, fairweather day, meteorological parameters.

\section{INTRODUCTION}

The atmospheric electric field at the earth's surface has been studied extensively [1]-[6]. From these studies, it has been well established that a negative electrical charge is present on the earth's surface and a positive charge at the ionosphere, also known as equipotential layer of the atmosphere. The field generated between these two regions is termed as the atmospheric electric field [7]. The fair-weather vertical atmospheric electric field is generated and maintained by solar irradiance, surface radioactivity, cosmic rays and thunderstorms. On an average, this has a magnitude between $100-120 \mathrm{Vm}^{-1}$ [8]. A fair-weather day is defined as a day with no local thunderstorm activity, no convective cloud formations at the site, wind speeds less than $5 \mathrm{~m} / \mathrm{s}$ and overall cloud coverage less than 3 okta.

The vertical component of the electric field Ez, gives rise to a potential gradient $\mathrm{F}$, that is $\mathrm{F}=-\mathrm{Ez}$. This sign convention is adopted so that, in locally undisturbed (fair-weather) atmospheric electrical conditions, $\mathrm{F}$ is positive [9].

The observation of atmospheric potential gradient could be explained by variations of atmospheric electrical conductivity with altitude and time [10]. The potential gradient close to the earth's surface or at an elevated height will be much influenced by the changes in electric field. The surface of the earth is negatively charged and the electric potential above the earth's surface is positive. Much of the variations in the potential gradient occur in the region below the exchange layer.
In case of fair-weather conditions, the potential difference with respect to the earth's surface increases with height rapidly and is of the order of hundreds of volts per meter. This increase of potential difference continues up to the height of the exchange layer whose height from the earth's surface normally varies from 0 to $3 \mathrm{~km}$ depending on the meteorological conditions. However, above this level, the increase in potential difference decreases probably due to increased conductivity [11]. Increase in potential difference with height slows down around the height of electrosphere, after which the increasing trend stops all together. The value of potential difference at this height about $50 \mathrm{~km}$ or so, (at the base of electrosphere) above the earth's surface is around 280 $\mathrm{KV}$. Above this is the ionosphere. The electrosphere and the ionosphere both are the regions where the ionization is maintained by the intense ultraviolet solar radiation.

As explained by [12], the atmosphere can be mathematically expressed as $\varepsilon_{0}(\mathrm{dF} / \mathrm{dh})=-\rho$, where $F$ is the vertical potential gradient $(\mathrm{V} / \mathrm{m}) ; \mathrm{h}$ is the vertical distance from the earth's surface (in meters); $\rho$ is the volume of density of charge $\left(\mathrm{C} / \mathrm{m}^{3}\right)$; and $\varepsilon_{0}$ is the permittivity of free space $(8.85 \mathrm{x}$ $\left.10-12 \mathrm{~F} / \mathrm{m}^{2}\right)$. When the vertical electric lines of force terminate on a conductor (and in present scenario the earth), then as a consequence, the surface charge density $(-\sigma)$ present will be given by $\varepsilon_{0} \mathrm{E}=\sigma$.

The generalized expression for space charge is given by $\varepsilon_{0}$ div $E=-\rho$, where $E$ is the electric field strength $(V / m)$. For surface density, the above could be simplified to $\varepsilon_{0} \mathrm{E}=\sigma$.

The two reasons for possible enhancement after sunrise are possibly due to advection and convection processes in the lower atmosphere. When convection gradually begins after sunrise it has a gradual effect on the electric field. Advection may be due to ion pairs generated by weak natural radioactivity released from soil, which could have a significant effect on the space charge near the ground [13].

The convection hypothesis depends on the physical location of the sensor. Thus at sunrise the heating of the ground begins due to solar irradiance and the temperature of the soil increases thereby causing an upwelling of aerosols which carry the space charge generated along with it, thereby an increase in the positive potential gradient. The local potential gradient is very much dependent on local air conductivity columnar resistance and the upper atmospheric potential. The atmospheric electric parameters therefore vary from day to day and have geographical distribution dependent on different regions [14]. 
The ultimate objective of the measurements at this high altitude station was to study and understand the atmospheric electrical parameters such as potential gradient, during different seasons, different local conditions and their interaction with various meteorological parameters.

In the study reported here, the emphasis is limited to the diurnal variation of fair-weather PG measurements for a total period of six months. This was divided into two parts, January to March 2017, and April to June 2017. This was carried out, along with relevant meteorological parameters and solar irradiance. The intent was to correlate the above parameters to arrive at a preliminary understanding of the variations of the atmospheric electric field and their interaction with meteorological parameters.

\section{INSTRUMENTATION}

The measurement of the atmospheric electric field was carried out at the Atmospheric Research Laboratory, School of Technology, NEHU, Shillong $\left(25^{\circ} \mathrm{N}, 91^{\circ} \mathrm{E}\right)$. The electric field was measured using a modified Wilson plate sensor. The basic principle of the plate sensor was as follows: The sensor was placed flush with ground and with the surface of the sensor facing the atmosphere above it, and collecting the charge incident on it. This charge is proportional to the equipotential field at the level and location of the sensor. When this charge is allowed to leak through a very high resistance (10M $\Omega)$, a voltage is produced across the high resistance which is proportional to the charge incident on the flat plate collector. The resultant voltage is sensed by a high input impedance electrometer. The output of the electrometer is connected to and recorded on a data logger.

This design is very similar to the setup implemented by [15], [16] and [17]. However the design implemented, is based on the version used by [17] (Figure. $1 \mathrm{a}, \mathrm{b}$ ).

The sensor was constructed using a copper clad double sided glass epoxy board. On one side of the board, the sensor area, guard ring and electrometer circuit was suitably etched. The copper cladding on the back side of the board was grounded. The copper cladding on that side was left intact, except the area occupied by the electrometer circuit on the sensor side. The sensor board, after protective tin plating was populated with the components of the electrometer circuit. The sensor board was then fixed on a Perspex sheet of the same size using four PVC standoff's and double sided insulating tape. This arrangement was in turn, fixed on a larger ceramic tile, using an additional four PVC standoffs. The voltage developed on the upper surface of the sensor was connected to the input of the onboard electrometer amplifier. The output of this amplifier was then connected to a coaxial cable leading down to the laboratory on the ground floor. This was then fed to a USB 201 data logger which sampled the input every second with a resolution of $\pm 10 \mathrm{mv}$ in the range of $\pm 10 \mathrm{~V}$. The sensor was placed on the terrace of the School of Technology building and located, $28 \mathrm{~m}$ above the ground level.

\section{CALIBRATION}

The calibration of the instrument was carried out using the following procedure. The complete assembly was placed on top of an aluminum sheet $(1 \mathrm{x} 1 \mathrm{~m})$. The lower part of the double sided copper clad glass epoxy board and the aluminum sheet was grounded to a common ground. Another aluminum sheet of the same dimension was placed above the sensor at a height of $1.2 \mathrm{~m}$. The upper aluminum sheet was connected to a DC power supply and a voltage applied to it which was varied from 0 to $300 \mathrm{~V}$ in step of $+50 \mathrm{~V}$. These steps of $+50 \mathrm{~V}$ were applied and allowed to stabilize for 15 minutes per step. The output of the sensor was recorded continuously and plotted to generate a calibration curve.

The atmospheric field measurements were recorded continuously from December 2016. Fair-weather days of atmospheric electric field were selected from each month's data set, subject to ideal conditions stated earlier. It should be noted that this region is subject to highly variable weather conditions. Especially during April-September, there is a predominance of disturbed days compared to fair-weather days. To assess the influence of solar radiation (UV), a photo sensor was also installed towards the end of March 2017. The output of the photo sensor was also fed to the data logger so that simultaneous measurements could be carried out continuously. Certain significant meteorological parameters such as temperature and relative humidity were also recorded with the help of an Arduino based temperature/relative humidity sensor.

(a)

(b)

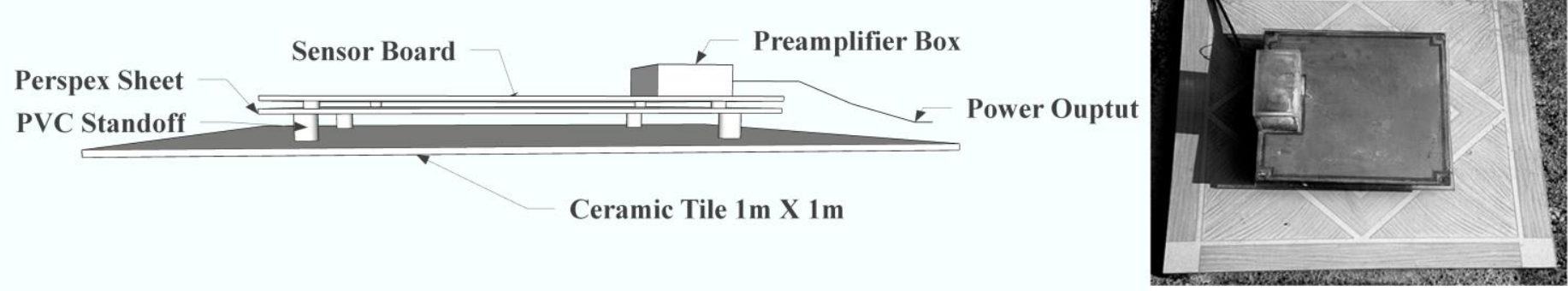

Figure 1 (a) Sketch of the PG module. (b) Photograph of the sensor board. 


\section{RESULTS}

The potential gradient data was recorded continuously ranging from 0-300 $\mathrm{Vm}^{-1}$. From this voluminous data, only six months data from January 2017 to June 2017 was used for the present analysis, is reported. Based on the above mentioned classifications of a fair-weather day, only 18 days were considered as fair-weather days. It may be noted that during the month of June 2017, not a single fair weather day was available. Fair-weather measurements showed a gradually rise in PG, ascending to a maximum around local noon. And in the evening around sunset, a rapid of drop of PG to the ambient level was noted. An example of the measurement of potential gradient versus temperature and relative humidity for is shown in Figure.2.
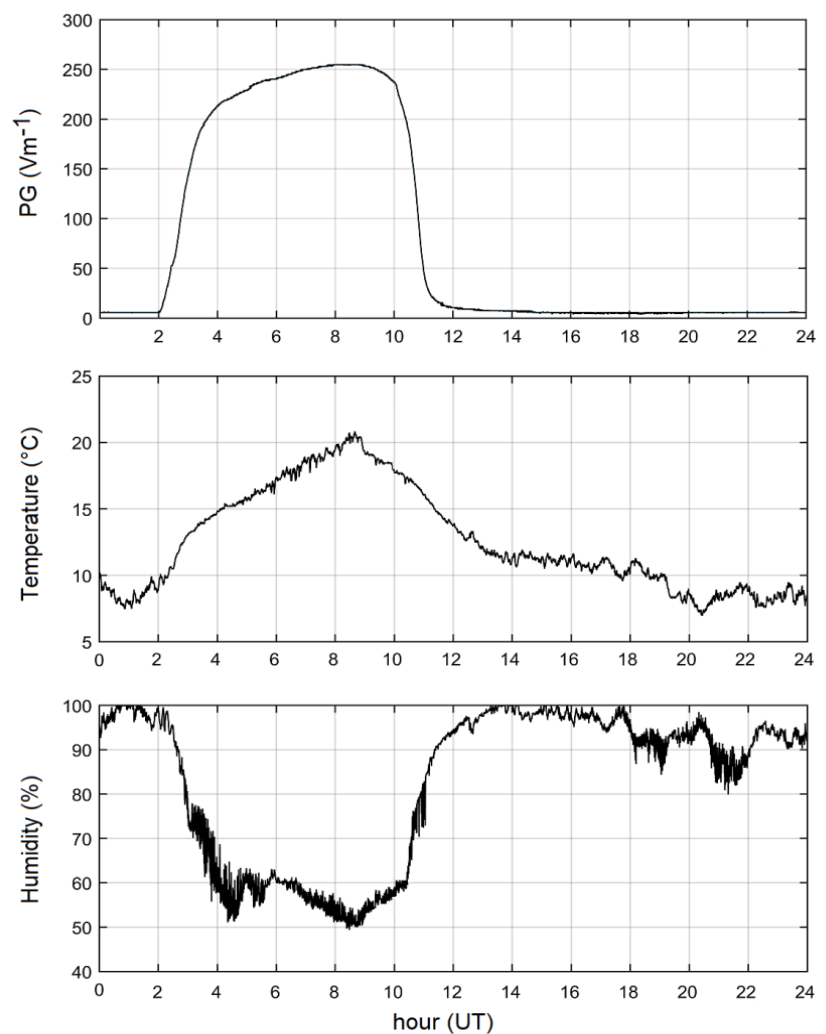

Figure 2. A sample response of fair-weather atmospheric electric field, temperature and humidity observed on 9th January 2017.

During these measurements, the significance of solar irradiance on the vertical electric field was noted. For the complete understanding of the electrical behavior of the vertical electric field relation with solar irradiance, as mentioned earlier, a solar irradiance or photosensor unit was installed during last week of March 2017. A typical plot of the parameters including solar intensity is shown in Figure.3.

For evaluation of the correlation between the meteorological parameters and solar irradiance with PG the six month data set was divided into two parts January, February, March (JFM) and April, May, June (AMJ). The diurnal variation of all these parameters was studied for these two periods.
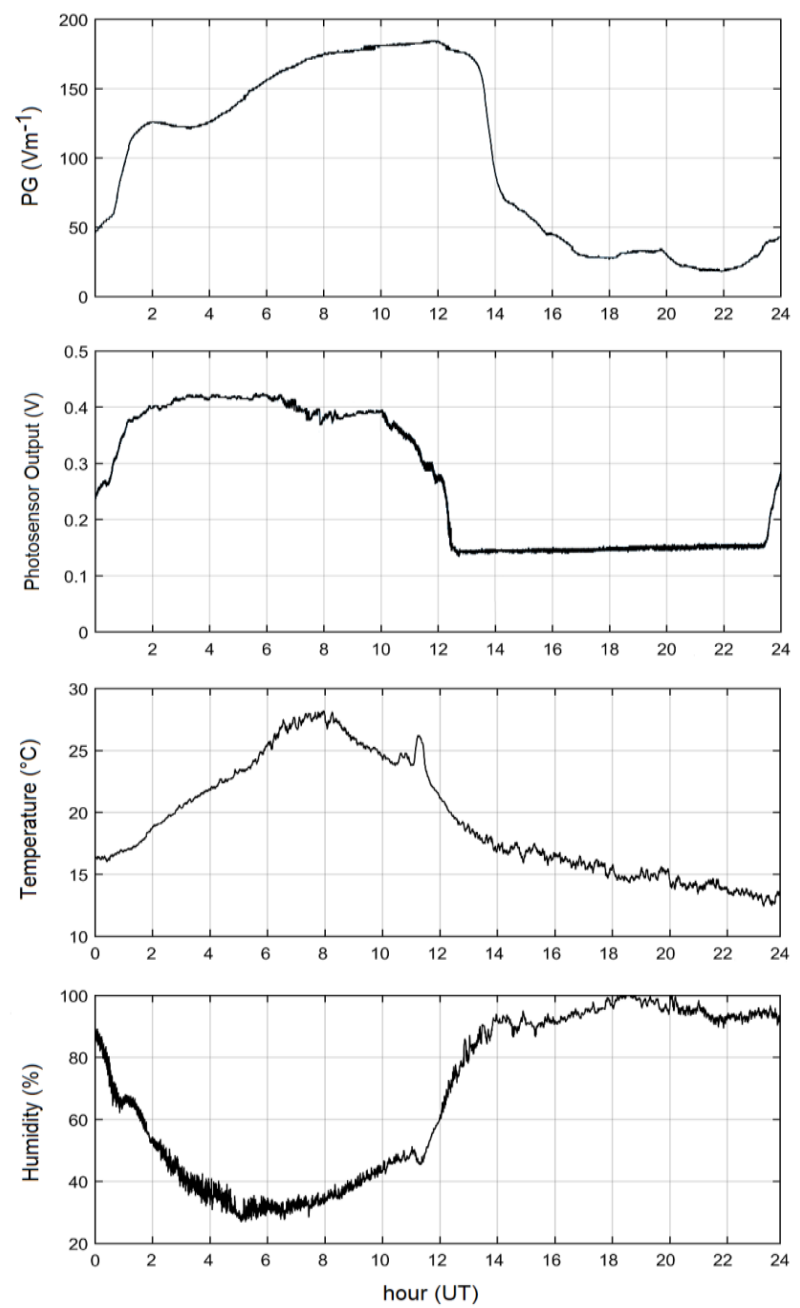

Figure. 3. Fair-weather atmospheric potential gradient, Photosensor output, Temperature and humidity observed on 10th April 2017.

The histogram of the data plot is presented for 18 days fairweather days (Figure.4). It was observed that for these 18 days, the fair-weather potential gradient hourly average is nearly $90 \mathrm{Vm}^{-1}$.

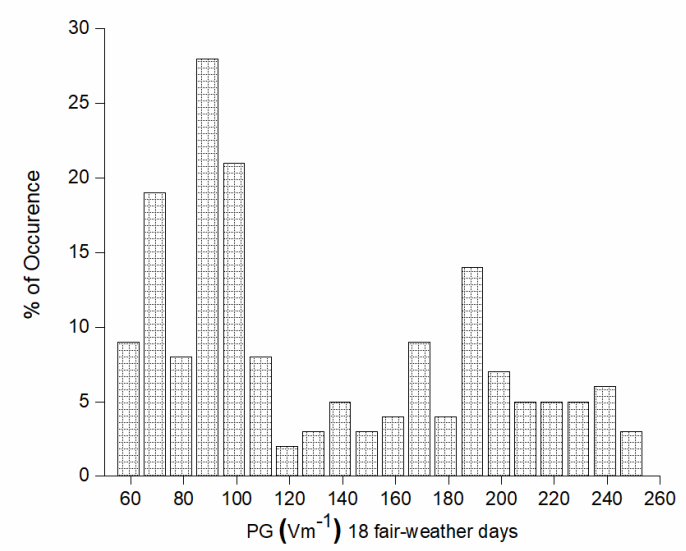

Figure 4. Histogram for the selected 18 fair-weather days. 
Figure.5 show that there is a shift in maximum potential gradient by about an hour between the average hourly values of JFM and AMJ curves. The same figure also shows the response of the irradiance photosensor during the period AMJ.

In the measurements and investigation of the local fairweather electric field, it was noted that it is strongly influenced by local meteorological conditions. This ground based fair-weather potential gradient data is very sparse, primarily because of the environmental conditions in which the station is located, with disturbed weather predominating over fair-weather conditions.

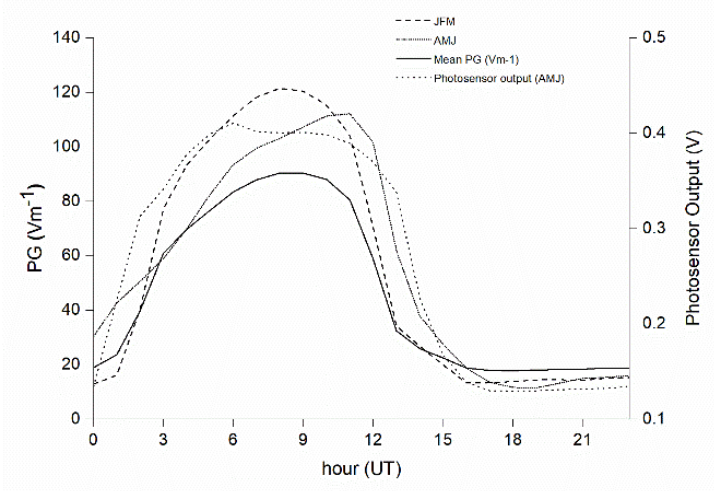

Figure 5. Plot of the relation of potential gradient, photosensor output during the period of study.

Regression analysis on the data was carried out on potential gradient values and meteorological parameters such as temperature and humidity during the period of study. The potential gradient for the JFM and AMJ periods in relation to temperature is shown in Figure. 6a, 6b. The potential gradient for JFM and AMJ periods in relation to relative humidity is shown in Figure.6c, $6 \mathrm{~d}$.
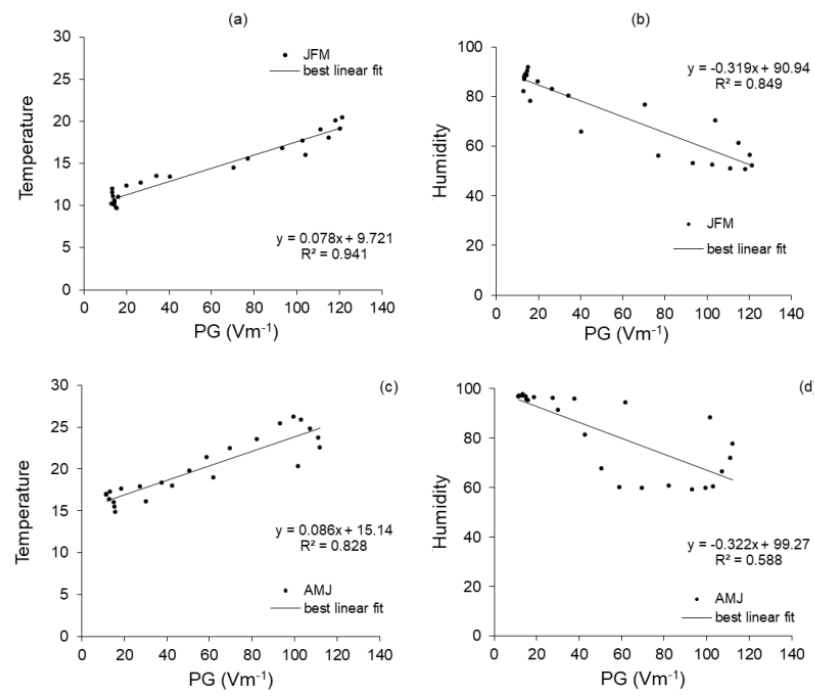

Figure. 6. Correlation plot of potential gradient relation with temperature and humidity. (a). Temperature relation with PG during the period JFM. (b) Humidity relation with PG during the period JFM. (c). Temperature relation with PG during the period AMJ. (d). Humidity relation with PG during the period AMJ.

Fair-weather potential gradient and temperature strongly correlate with correlation coefficient 0.95 and $\mathrm{p}<0.001$. The potential gradient relationship with humidity shows a negative correlation coefficient -0.86 and $\mathrm{p}<0.001$.

Figure.7 shows the day to day diurnal fair-weather variations observed during the period of study. The first plot corresponds to the period JFM and the latter shows the period AMJ.
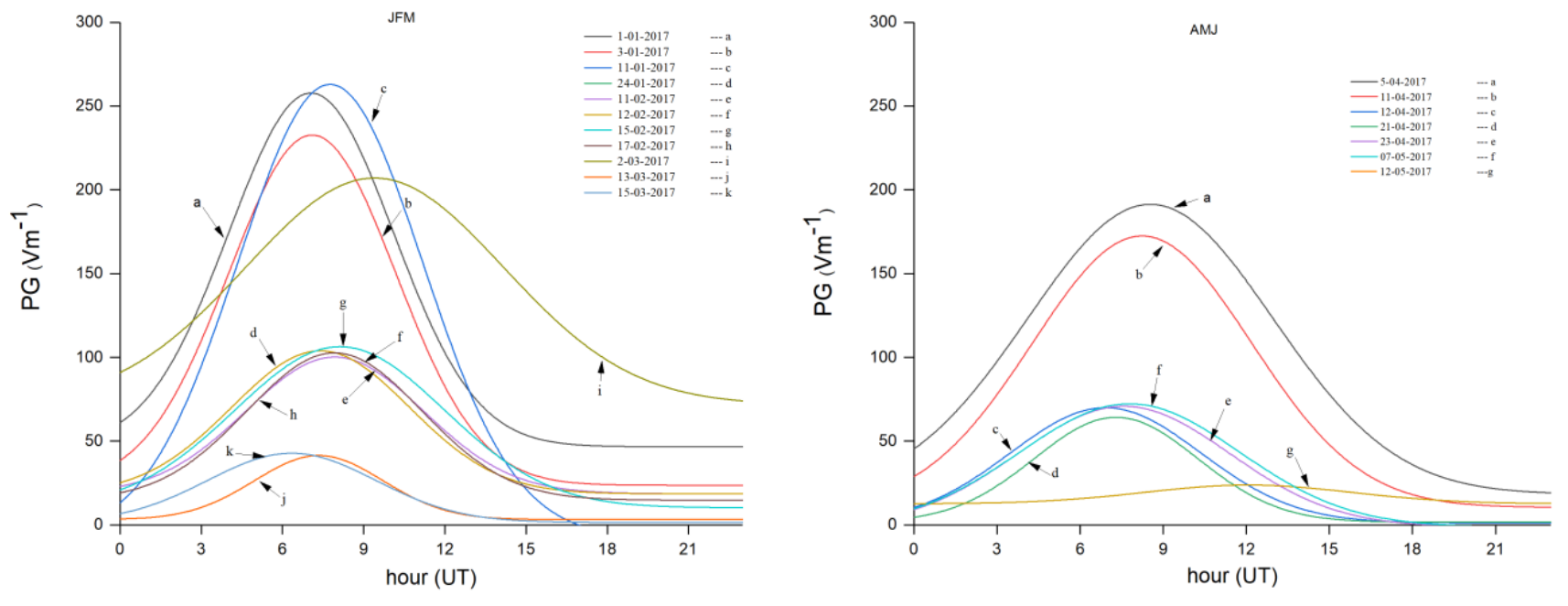

Figure. 7. Fair-weather variation of 18 days during the period of study JFM and AMJ. (However, there were no fair weather days available in the month of June 2017). 


\section{DISCUSSIONS}

In the period of six months of the study considered here, the occurrence of disturbed weather days was much higher than fair-weather days. Out of six month data (181 days) considered, only 18 day fair-weather data could be obtained.

From the data obtained during the period of study an attempt was made to evaluate the possible linkages between atmospheric potential gradient, solar irradiance, temperature and humidity.

The day to day variability in potential gradient observed at this high altitude station was very much dependent on local climatic changes, rainfall and intermittent and extensive cloud coverage [18]. The variability was also greatly influenced by other meteorological parameters, surface topography, and solar irradiance.

This is quite evident from the two sample records of Figure. 2 and Figure. 3. On $9^{\text {th }}$ January 2017 (Figure.2), around 0200 UT, the potential gradient values increased very quickly and after $0400 \mathrm{UT}$, there was a slow increase in PG values and continued up to about 1000 UT after which there was a sharp decrease in PG values. By 1200 UT it had reached to a few volts $/ \mathrm{m}$. On the contrary to this, on $10^{\text {th }}$ April 2017, (Figure.3), one can observe that PG value was $50 \mathrm{~V} / \mathrm{m}$ at 0000 UT. It slowly increased and there was a hump in PG value around 0200 UT, followed by slight decrease in PG for two hours after which it again slowly picked up the increasing trend, and after $0800 \mathrm{UT}$, it almost stabilized for a while. PG value was around $190 \mathrm{~V} / \mathrm{m}$ at $1200 \mathrm{UT}$ after which a slow decrease in PG took place. On this particular day, it was observed that PG values did not go down to a few $\mathrm{V} / \mathrm{m}$ but remained around $30-40 \mathrm{~V} / \mathrm{m}$. This indicates that after sunset at the site, the usual removal of charges due to rapid recombination did not occur.

After sunrise the gradual increase in potential gradient could be attributed to effect of solar irradiation on the lower atmosphere, formation of atmospheric D, E layers and charging of the boundary layer. In addition to this, an increase in the potential gradient is attributed to increase in small positive ions which are carried upward by convection initiated by sunrise in the local region.

By local noon, the potential gradient values reach a maximum and remain stable due to the equilibrium that is established at the boundary layer [19]. A gradual decrease in potential gradient in the afternoon could be due to removal of ions by aerosols leading to increasing conductivity.

The data obtained showed significant variations of local potential gradient, the temperature and solar irradiance [20]. The variation of potential gradient observed during the period of study, the peak magnitude shifted from 8:00 UT to 11:00 UT, which could be attributed to the change in the length of the day and increases with solar irradiance as shown in Figure 7(a) and (b). Further, one can observe the variation in peak magnitudes of PG on different fair weather days, and secondly, it is much more pronounced during JFM period than during AMJ period.
The actual dynamics involved needs further extended study as the JFM values appear to be higher compared to AMJ months. The AMJ values are severely constrained by the disturbed conditions due to influx of the monsoon at this location.

\section{CONCLUSIONS}

In this study, the correlation between the potential gradient with the meteorological parameters such as temperature and humidity was carefully examined. Atmospheric electric field data collected at Atmospheric Research Laboratory, Shillong station was carried out for the first time and shows the following:

i. On fair-weather days the potential gradient exhibited positive correlation with temperature.

ii. On fair-weather days the potential gradient exhibits negative correlation with humidity.

iii. The mean potential gradient was observed to be around $90 \mathrm{Vm}^{-1}$ during fair-weather days.

iv. Statistical evaluation showed that local meteorological parameters affect the potential gradient.

v. Solar irradiance greatly influenced the potential gradient during fair-weather days.

vi. The variability in potential gradient on day to day basis was significant and needs further detailed investigation which is being continued.

As there are many parameters involved continuing long term measurements are necessary, to study and understand the behavior of the local potential gradient and its dependence on the prevalent climate over this sub Himalayan region.

\section{Acknowledgments}

The authors record their thanks to Dr. Alec Bennett, Meteorological Products Manager, Visiting Research Fellow (University of Bath), Bristol, UK for permission to use the design used by him for atmospheric electric field measurements. The study was funded and supported by Department of Basic Sciences and Social Sciences, North-Eastern Hill University. The first author would like to thank the UGC, Govt. of India for Rajiv Gandhi National fellowship during the course of research.

\section{REFERENCES}

[1] R. R. Agarwal and N. C. Varshneya, "Global electric circuit parameters over Indian subcontinent," Indian Journal of Radio \& Space Physics, vol. 22, pp. 320-324, 1993.

[2] G. B. Burns, B. A. Tinsley, A. V. Frank-Kamenetsky, O. A. Troshichev, W. J. R. French, and A. R. Klekociuk, "Monthly diurnal global atmospheric circuit estimates derived from Vostok electric field measurements adjusted for local meteorological and 
solar wind influences," Journal of the Atmospheric Sciences, vol. 69, no. 6, pp. 2061-2082, 2012.

[3] A. Guha, B. K. De, S. Gurubaran, S. S. De, and K. Jeeva, "First results of fair-weather atmospheric electricity measurements in Northeast India," Journal of earth system science, vol. 119, no. 2, pp. 221-228, 2010.

[4] A. Kumar, J. Rai, M. J. Nigam, A. K. Singh, and S. Nivas, "Effect of orographic features on atmospheric electrical parameters of different cities of India," Indian Journal of Radio \& Space Physics, vol. 27, pp. 215223, 1998.

[5] F. Märcz and R. G. Harrison, "Long-term changes in atmospheric electrical parameters observed at Nagycenk (Hungary) and the UK observatories at Eskdalemuir and Kew," in Annales Geophysicae, 2003, vol. 21, pp. 2193-2200.

[6] D. G. Yerg and K. R. Johnson, "Short-period fluctuations in the fair-weather electric field," Journal of Geophysical Research, vol. 79, no. 15, pp. 21772184, 1974.

[7] L. Wahlin, "Elements of fair weather electricity," Journal of Geophysical Research: Atmospheres, vol. 99, no. D5, pp. 10767-10772, 1994.

[8] B. F. J. Schonland, Atmospheric Electricity, 2nd edition. New York: John Wiley \& Sons, Inc., 1953.

[9] R. G. Harrison and K. A. Nicoll, "Fair weather criteria for atmospheric electricity measurements," Journal of Atmospheric and Solar-Terrestrial Physics, vol. 179, pp. 239-250, 2018.

[10] C. G. Stergis, G. C. Rein, and T. Kangas, "Electric field measurements in the stratosphere," Journal of Atmospheric and Terrestrial Physics, vol. 11, no. 2, pp. 77-82, 1957.

[11] R. C. Sagalyn and G. A. Faucher, "Space and time variations of charged nuclei and electrical conductivity of the atmosphere," Quarterly Journal of the Royal Meteorological Society, vol. 82, no. 354, pp. 428-445, 1956.

[12] R. A. Roos, The forgotten pollution. Springer Science \& Business Media, 1996.

[13] T. C. Marshall, W. D. Rust, M. Stolzenburg, W. P. Roeder, and P. R. Krehbiel, "A study of enhanced fairweather electric fields occurring soon after sunrise," Journal of Geophysical Research: Atmospheres, vol. 104, no. D20, pp. 24455-24469, 1999.

[14] T. Ogawa, "Fair-weather electricity," Journal of Geophysical Research: Atmospheres, vol. 90, no. D4, pp. 5951-5960, 1985.

[15] M. R. Cummings, H. W. Nicholson Jr, and D. R. Porto, "Measurement of the atmospheric electrostatic potential gradient near sea level," American Journal of Physics, vol. 49, no. 12, pp. 1178-1180, 1981.
[16] L. W. Brown, "Two experiments to measure the electric field at the Earth's surface and the variation of potential difference with height," Physics Education, vol. 20, no. 6, p. 287,1985 .

[17] A. J. Bennett and R. G. Harrison, "A simple atmospheric electrical instrument for educational use," geo-ph, vol. 13, pp. 1-15, 2007.

[18] A. J. Bennett and R. G. Harrison, "Variability in surface atmospheric electric field measurements," in Journal of Physics: Conference Series, 2008, vol. 142, p. 012046.

[19] G. I. Moller, "Atmospheric Electric Potential Gradient," American Journal of Physics, vol. 32, no. 5, pp. 386386, May 1964.

[20] Y. Xie, J. Wu, Y. Xu, T. Zhang, and X. Liu, "Variation of fair weather atmospheric electricity in Jinghong Observatory, China," in Lightning Protection (ICLP), 2014 International Conference o, 2014, pp. 727-729. 